\title{
Measuring zero water level in stream reaches: A comparison of an image-based versus a conventional method
}

\author{
Amelie Herzog ${ }^{1}$, Kerstin Stahl ${ }^{1}$, Veit Blauhut ${ }^{1}$, and Markus Weiler ${ }^{1}$ \\ ${ }^{1}$ University of Freiburg
}

January 20, 2022

\begin{abstract}
Process understanding of the interaction between streamflow, groundwater and water usages under drought are hampered by a limited number of gauging stations, especially in tributaries. Recent technological advances facilitate the application of noncommercial measurement devices for monitoring environmental systems. The Dreisam River in the South-West of Germany was affected by several hydrological drought events from 2015 to 2020, when parts of the main stream and tributaries fell dry. A flexible longitudinal water quality and quantity monitoring network was set up in 2018. Among other measurements it employs an image based method with QR codes as fiducial marker. In order to assess under which conditions the QR-code based water level loggers (WLL) deliver data according to scientific standards, we present a comparison to conventional capacitive based WLL. The results from 20 monitoring stations reveal that the riverbed was dry for $>50 \backslash \%$ at several locations and even for $>70 \backslash \%$ at most severely affected locations during July and August 2020, with the north western parts of the catchment being especially concerned. Thus, the highly variable longitudinal drying patterns of the stream reaches could be monitored. The image-based method was found to be a valuable asset for identification of confounding factors and validation of zero level occurrences. Nevertheless, a simple image processing approach (based on an automatic thresholding algorithm) did not compensate for errors due to natural conditions and technical setup. Our findings highlight that the complexity of measurement environments is a major challenge when working with image-based methods.
\end{abstract}

\section{Hosted file}

subm_version_manuscript_AHerzog.pdf available at https://authorea.com/users/456382/articles/ 553448-measuring-zero-water-level-in-stream-reaches-a-comparison-of-an-image-basedversus-a-conventional-method 
figures/Figure1/Figure1-eps-converted-to.pdf

\section{Hosted file}

Figure2.eps available at https://authorea.com/users/456382/articles/553448-measuring-zerowater-level-in-stream-reaches-a-comparison-of-an-image-based-versus-a-conventionalmethod 
figures/Figure3/Figure3-eps-converted-to.pdf 
figures/Figure4/Figure4-eps-converted-to.pdf 
figures/Figure5/Figure5-eps-converted-to.pdf 
figures/Figure6/Figure6-eps-converted-to.pdf 
figures/Figure7/Figure7-eps-converted-to.pdf 